\title{
Self Perceptions of Students' Humanities-Based Skills in an Engineering Program: Overview of First Year RESULTS
}

\author{
Laura Patterson \\ University of British Columbia \\ Laura.patterson@ubc.ca
}

\begin{abstract}
Demonstrating and improving assessment of humanities-based graduate attributes can be challenging, as there are no easy metrics in order to do so. Engineering programs offer curricular and co-curricular programming in order to improve these attributes in their students and still find it challenging to determine if those initiatives are in fact effective. To those ends, in order to assess engineering accreditation humanities-based skills, a threeyear longitudinal study was implemented at a medium sized engineering school at a large research university. In particular, the survey focuses on engineering students selfperceptions of teamwork, communication skills, engineering ethics, professionalism, and lifelong learning in order to gather quantitative data that can be analysed for trends. This paper overviews the data gathered in the first year of the longitudinal study and offer preliminary explanations of those results and what they can offer to our understanding of humanities-based graduate attributes offered in our engineering programs.
\end{abstract}

Keywords: CEAB graduate attributes, student selfperceptions, longitudinal study, engineering education

\section{INTRODUCTION}

Engineering programs are looking for ways of integrating and quantifying humanities-based graduate attributes such as communication, professionalism and teamwork. While various curricular and co-curricular methods are employed by engineering programs to help address these attributes, it has been identified that these humanities-focused accreditation requirements are difficult to isolate and assess [6].

This research offers another metric to examine the effectiveness of engineering programs and meeting humanities-based accreditation requirements by assessing students' perceptions of their abilities in those areas at different points in their program. While student selfperceptions may not be the main concern of the Canadian Engineering Accreditation Board, student self-efficacy has been found to be correlated with student success over the long term $[1,5]$. While students' self-efficacy is not necessarily an indicator of learning, this metric is not meant to replace other initiatives demonstrating curriculum effectiveness, but is instead meant to offer aggregated quantitative data that provides a fuller picture in order to understand how students view their own abilities in these core areas.

This study was first designed as a pilot in 2016 to test a co-curricular initiative at the University of British Columbia's School of Engineering to integrate humanitiesfocused graduate attributes into an engineering program, Introduction to Engineering (i2E), for all first-year engineering students to introduce the graduate attributes that support personal and professional development, including teamwork, ethics, and lifelong learning. Originally, i2E was embedded in the first year of study (specifically in a first-year, first-term drawing course and a first-year, second-term design course) and developed further in three pillar courses (second-year design, thirdyear project management, and fourth-year capstone). Recently, an online version has been explored as well. I2E introduces students to core concepts that will support their academic and professional success: individual and teamwork skills, professionalism, ethics and equity, and lifelong learning [3].

The information gathered from the pilot was found to be useful to understanding the co-curricular initiative and scalable. Therefore, the metric was revised and approved for a three-year longitudinal study that would include all years of study beginning in the fall of 2017. The purpose of the present study is to improve instructors' understanding of the perceptions of engineering students across all years of study to determine if and how these perceptions change after exposure to such initiatives the first year. At the time of this paper, the longitudinal study is halfway through its second year, so the focus of this paper will be limited to the results of the first year, 2017/2018. 


\section{RESEARCH DESIGN AND METHODS}

There were two phases of data collection in the first year of the study. Participants were recruited from engineering courses at the institution in September 2017 and April 2018. In September of 2017, the Year 1 students were surveyed in order to get a baseline of self-perception upon entry into their engineering program. These two groupings of the Year 1 students was to isolate students before and after participating in that year's i2E program. In April of 2018, as classes were ending for the year, the Year 1 students were surveyed again using the same 14 Likertstyle questions. To get a broader perspective of student self-perceptions, engineering students in Years 2, 3, and 4 of their program were also asked to participate in the same survey in order to see how these students perceived their abilities in the same attributes. These upper year students were added in the longitudinal study both to understand how different years perceived their self-efficacy in the tested areas as well as to track the cohorts who participated in $\mathrm{i} 2 \mathrm{E}$ and compare them with students at the same point in their program, but who had not participated in i2E.

Students were only excluded if they declined to consent to the study, or agreed, but then did not complete the whole survey. As a result, in the pre survey for Year 1 in September $2017 \mathrm{n}=244$, and in the post survey run in April 2018 are as follows: Year $1 \mathrm{n}=72$, Year $2 \mathrm{n}=78$, Year 3 $\mathrm{n}=56$, and Year $4 \mathrm{n}=75$.

The institution's behavioral research ethics board approved the study.

Participants were surveyed on their self-efficacy of humanities-based graduate attributes, as self-efficacy in communication and other professional skills is one indicator of competency. The computer-based survey consisted of 14 Likert-style questions on a 4-point scale, (plus demographic information), regarding the following attributes: Teamwork, Leadership, Ethics, Professionalism, Lifelong Learning, Community Responsibility, and Communication Skills. Some of these attributes directly relate to Canadian engineering graduate attributes (i.e., Professionalism), while others pinpoint subissues within those attributes (i.e., Community Responsibility) [2]. Quantitative metrics were chosen to observe the overall aggregated trends of students' selfefficacy in these areas. Likert statements were both positively and negatively worded to add to the validity of the findings. This longitudinal study was executed after a pilot study had been completed the previous year to test the viability of the questions. Though the pairs of questions do not encompass all elements of each graduate attribute tested as indicated by Canadian Engineering Accreditation Board, the question pairs do indicate core skill sets that are necessary to demonstrating these graduate attributes as noted by the CEAB [2].

\section{RESULTS AND DISCUSSION}

The participants' average ratings of self-efficacy for teamwork are shown in Figure 1. Students across all years identified as having high self-efficacy in their own teamwork abilities overall, and they somewhat disagree that they struggle to deal with difficult teammates.

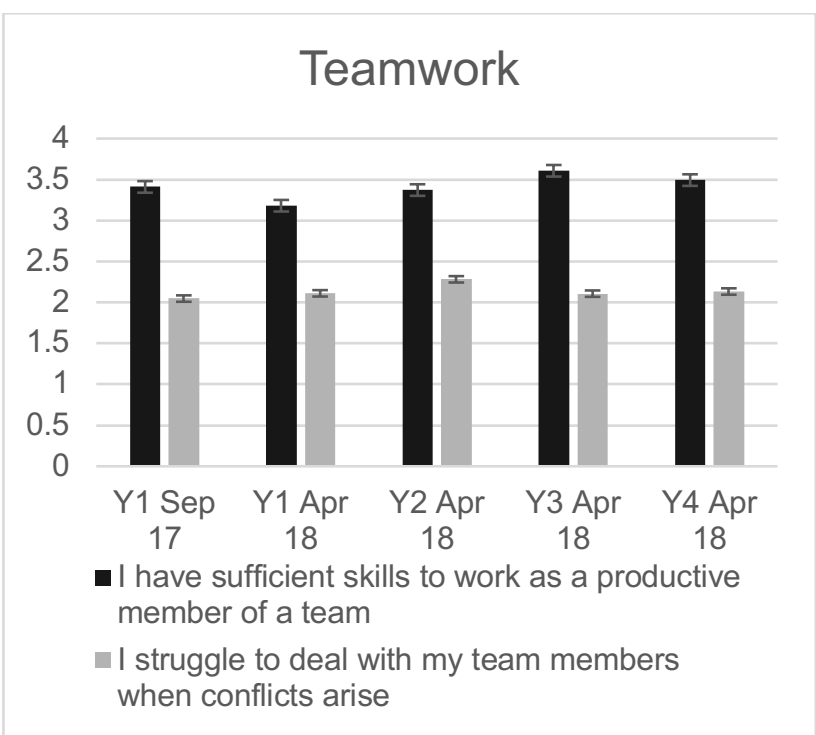

Fig. 1. Students' self-efficacy surrounding teamwork across all years of study.

Participants' self-efficacy surrounding their leadership abilities are shown in Figure 2. Participants consistently rate themselves as reasonably self aware in their leadership skills, and do not believe they have difficulty in understanding others. 


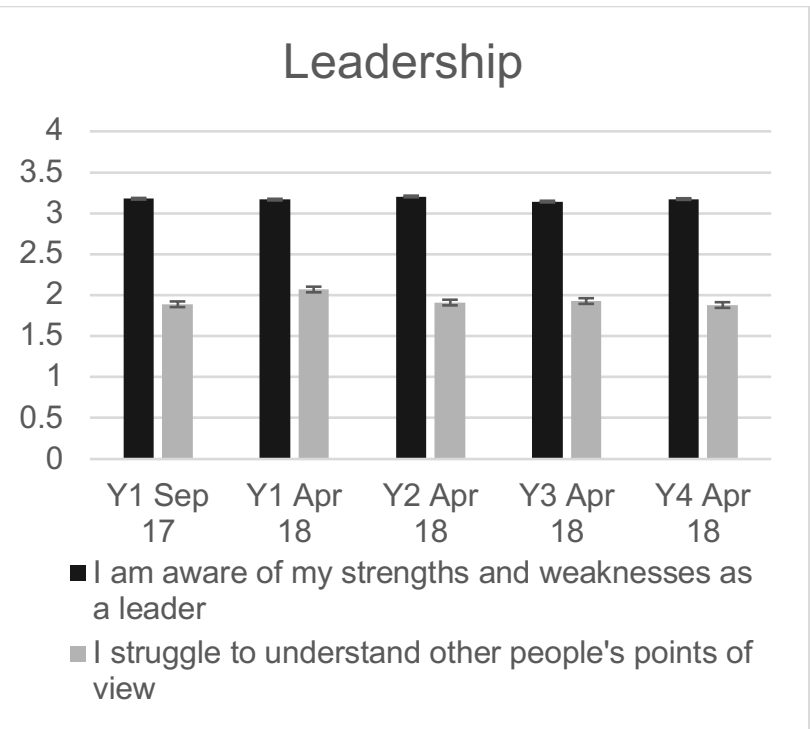

Fig. 2. Students' self-efficacy surrounding leadership across all years of study.

Figure 3 shows an increase in participants' self-efficacy in knowing engineering ethics from year to year in the study. Similarly, there is a clear and corresponding decrease in their confusion about where to seek support for ethical dilemmas.

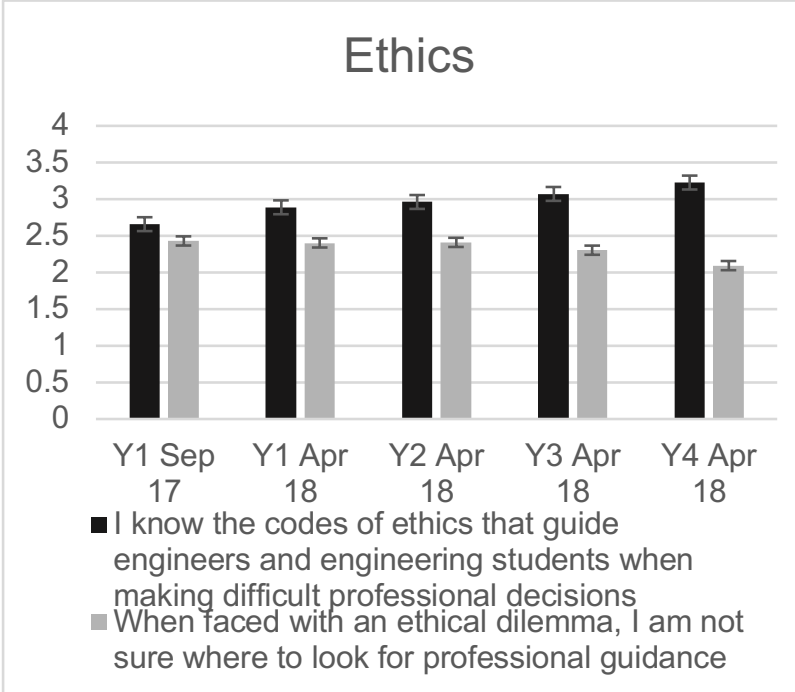

Fig. 3. Students' self-efficacy surrounding ethics across all years of study.

Figure 4 shows a consistently high level of consistency of participants' beliefs that they must contribute to a solution to a problem, even if they are not at fault. While these are not mutually exclusive statement, there is a slight increase over the years of study that the person at fault needs to take responsibility for it.

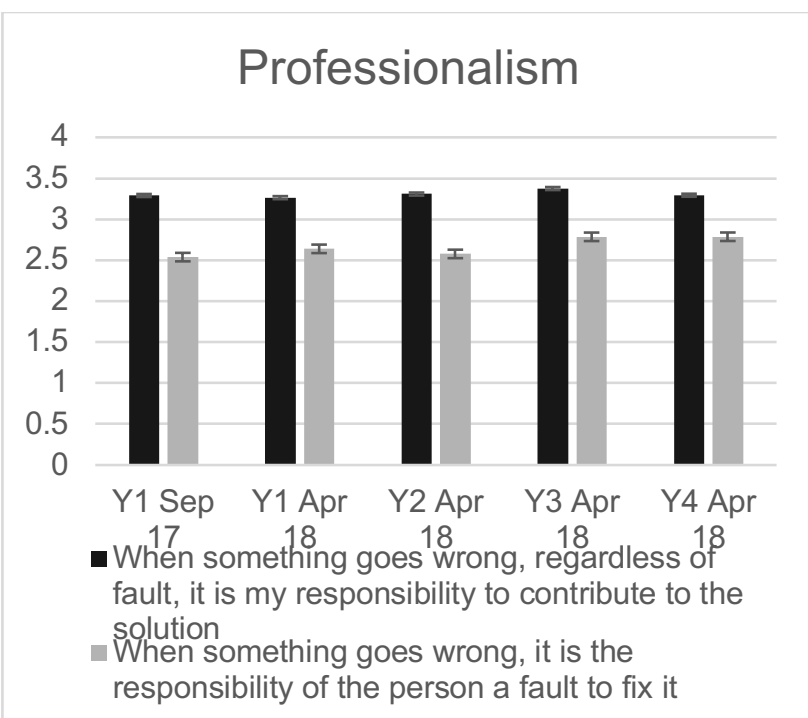

Fig. 4. Students' self-efficacy surrounding professionalism across all years of study.

When asked about their interests in lifelong learning, participants in all years generally agreed that they were interested in pursuing educational opportunities outside their formal education, as seen in Figure 5. With the lowest overall numbers in all years, participants overall strongly disagreed that they had not interest in learning outside of their formal education.

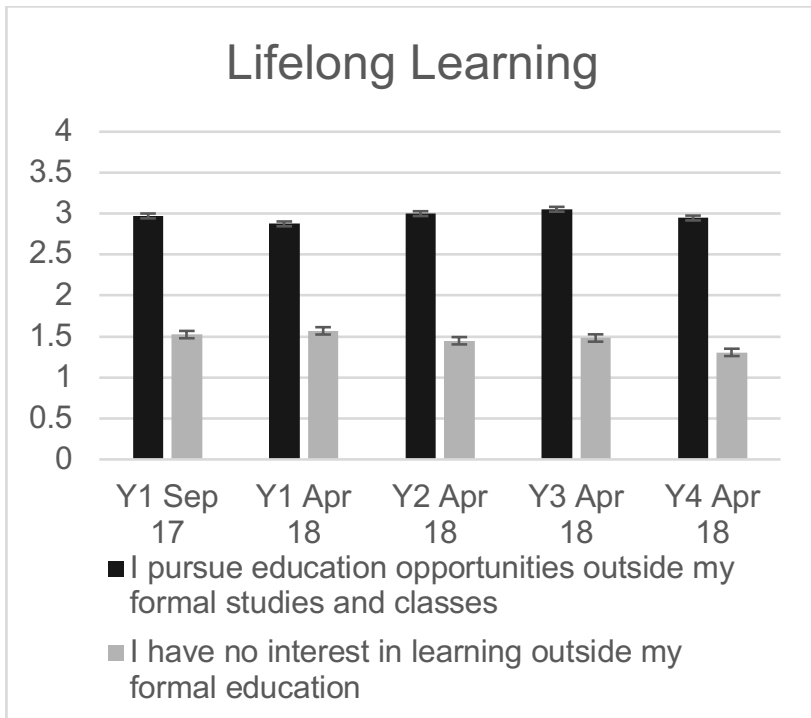

Fig. 5. Students' self-efficacy surrounding lifelong learning across all years of study.

As seen in Figure 6, participants responded quite similarly to statements regarding whether they make a decision based on the effect on the community or on themselves. Community responsibility seems to decrease slightly by Years 3 and 4, while self-interest stays quite consistent across all years. 


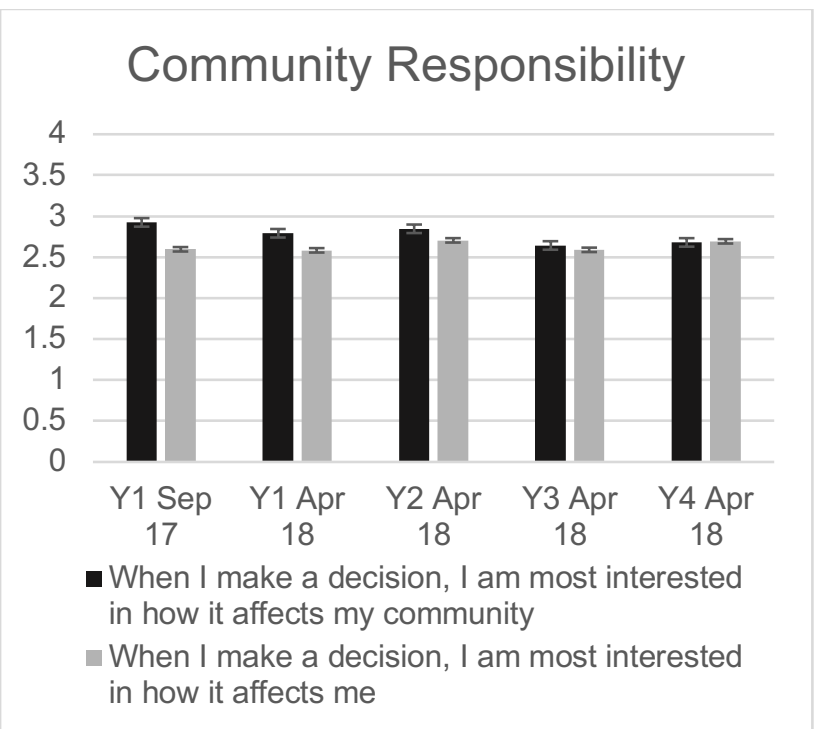

Fig. 6. Students' self-efficacy surrounding community responsibility across all years of study.

Participants' self-efficacy in their communication skills increases markedly from year to year as seen in Figure 7. A corresponding decrease from year to year is noted in their insecurity regarding their ability to communicate as an engineer.

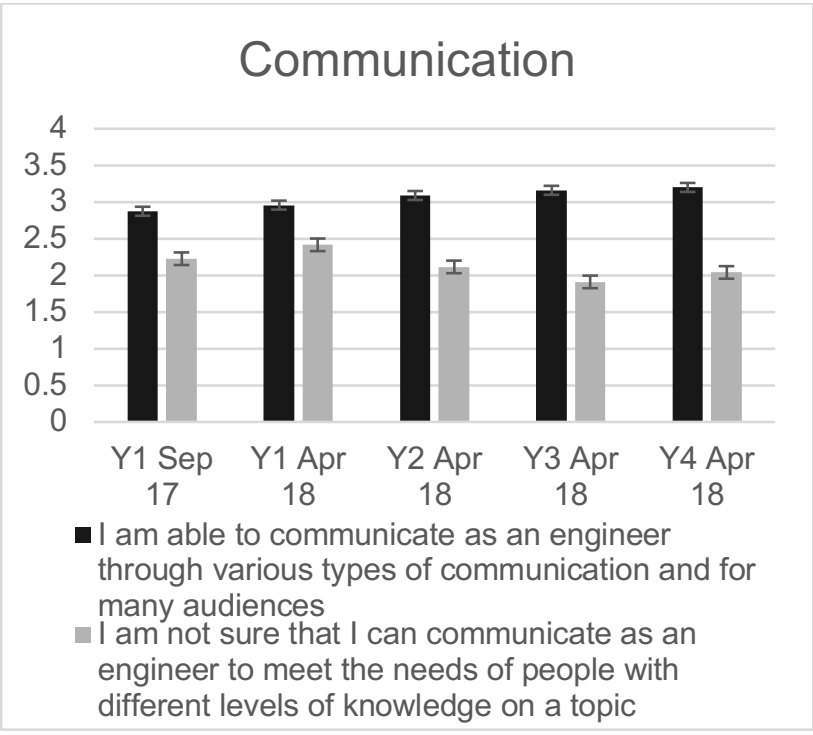

Fig. 7. Students' self-efficacy surrounding communication across all years of study.

Some overall patterns can be observed from this first year's worth of data. Clear and growing divergences from the positively worded statements to the negatively worded statements (ie. Ethics, Communication) suggests that elements of the engineering program may be increasing students' self-efficacy in those areas. Large gaps between the positively worded statements and the negatively worded statement (ie. Teamwork, Leadership, Lifelong Learning) may suggest that their education may not be affecting these attributes, or that students have already established opinions of themselves in those areas. Closer margins and consistency of responses across all years seem to correlate with statements that can be read as not entirely mutually exclusive (ie. Professionalism, Community Responsibility). As can be seen by the error bars in each of the graphs, there is a relatively narrow margin for error in each of these mean scores.

\section{CONCLUSIONS}

Though these findings are limited as student selfperceptions, self-efficacy is an important factor to future success in these humanities-based skills [1,5]. Preliminary observations from the results from the first year include increasing self-efficacy in engineering ethics and communication skills, and stable self-perceptions of teamwork and leadership skills, in addition to their interest in lifelong learning. Given that some of these years do not have baselines to compare individual cohorts, the comparisons made here are only to provide a preliminary understanding of the data and cohorts will be more appropriately isolated as we analyze the upcoming data from the following two years of the study. Professionalism and community responsibility seem to be more complex as seemingly opposite statements are not mutually exclusive. Wording changes to future iterations of the survey might clarify; however, qualitative would likely be more instructive of student experience.

The results from the first year were used as a part of the University of British Columbia's, School of Engineering's accreditation report to provide a fuller picture of student perceptions around their competence in humanities-based graduate attributes. This is the first year of the study so the findings are limited; however, we will be able to see if trends continue from year to year or differ based on students who experienced differing curricular and cocurricular initiatives. In particular, this data will be applied to the $\mathrm{i} 2 \mathrm{E}$ initiative as it develops as well. Anecdotally, the i2E program has been revised since the first year, but we will need to examine the longitudinal data to understand its impact on these graduate attributes.

This metric is certainly useable by other engineering programs in Canada and internationally. This survey has already been used by an institution in the United States to test students' self-efficacy after participating in a curricular initiative [4].

The next steps for this research are completing the last two years of the longitudinal study and analyzing the data for more significant trends. Future research could include qualitative data, such as interviews and focus groups from each group tested to help explain trends observed in the data. 


\section{Acknowledgements}

This work would not be possible without Carolyn Labun who created the original i2E program, and Jannik Eikenaar, Cathi Shaw, Megan Lochhead, and Samantha Luckow who were involved in the design and implementation of $\mathrm{i} 2 \mathrm{E}$ and the longitudinal study.

\section{References}

[1] Albert Banduara, "Self-efficacy: Toward a unifying theory of behavioral change," Psychological Review, vol. 84, no. 2, pp. 191-215, 1977.

[2] Engineers Canada, Canadian Engineering Accreditation Board: 2017 Accreditation Criteria and Procedures, 2017. Retrieved March 3, 2019 from https://engineerscanada.ca/sites/default/files/accreditat ion-criteria-procedures-2017.pdf

[3] Laura Patterson, Jannik Eikenaar, and Carolyn Labun, "Teaching and assessing 'Lifelong learning" in engineering communication courses," in Proc. of CEEA Canadian Engineering Education Conf., (Halifax, NS; 19-22 June 2016), 7 pp, 2016.

[4] Laura Patterson and Elaine Wisniewski, "Baseline selfefficacy of graduate attribute competencies in first-year engineering students in the United States and Canada," in Proc. IEEE Professional Communication Conference (Toronto, ON; 22-25 July 2018), 2 pp, 2018.

[5] Dale H. Schunk, "Self-efficacy and academic motivation," Educational Psychologist, vol. 26, no. 3 \& 4, pp. 207-231, 1991.

[6] Larry J. Shuman, Mary Besterfield-Sacre, and Jack McGourty, " The ABET 'Professional Skills' - can they be taught? Can they be assessed?" Journal of Engineering Education, vol. 94, no. 1, pp. 41-51, 2005. 